\title{
Modeling of Political Governance Indexes in the Issue of Collective Decision-Making by Consensus
}

\author{
Prof. Claver Boundja* \\ Political Manager and Focal-Point / Congo. From the African and Malagasy Council for University Education \\ (CAMES). Marien N'gouabi University Brazzaville /Congo
}

*Corresponding Author: Prof. Claver Boundja, Political Manager and Focal-Point / Congo. From the African and Malagasy Council for University Education (CAMES). Marien N'gouabi University Brazzaville /Congo

\begin{abstract}
All human organization is carried, consciously or unconsciously, by a form of governance. It is now well known in the media that everywhere in the world, human organizations, whether private, public or civic, take the helm themselves to govern themselves. The promotion of the concept of governance in recent years is undoubtedly linked to the consideration of political power in economic analysis on the one hand, and the link between the State, civil society and the market on the other. Our approach insists on the ethical status for all those who want to lead others in society. We therefore propose modeling the moral index of leaders. The objective of this paper is to propose a model of political governance, based on collective decision by concession, within the issue of the modernization of traditional Bantu governance practices. We analyze the collective decision from a political and philosophical point of view. This means that we are interested in the voting rules and the conditions of rationality in collective decisions. We start by explaining the concept of decision; we then analyze the mathematical model adapted to our political theory, namely Bantucracy; we finally propose three indexes: the governing morality index (GMI), the index of national governance (ING), and the index of general governance (IGG).
\end{abstract}

Key words: political governance indexes, collective decision-making, consensus, Bantucracy.

\section{INTRODUCTION}

The problem of good governance is today topical (Warren 2017). The news of governance is, in many ways, a celebration of the downfall of political and economic liberalism, a funeral celebration of mercantile democracy (Széll 2018). In such a context, where the governance of people, like money, is subject to fluctuating speculation of stock market values and the probabilistic game of financial markets, humans have slipped away from their particular value, to vegetate in moral recession (Achen $\&$ Bartels 2016). The world now seems to be brought together in a new order, that of the inability of rulers to deal with crises of all kinds: it is unanimity of incompetent politicians. Among political actors, the question of the governance of society is now locked in the management of public opinion by the media, without an analysis of governance models and alternative political regimes (Foa \& Mounk 2016).

With the media dramatization of political and economic crises, artificial pandemics, armed conflicts and their procession of undertakers, it would be fairer to say that the mornings of the Western model of society are behind us (Peter 2011). To be realistic today would be to accept the liquidation of liberalism and capitalism, to open up to the governance of good people, for human well-being, based on consensus, which we call Bantucracy (Boundja 2019). And collective decision by consensus is the way we propose for the choice of leaders at all levels of society.

Collective decisions making is the ability of individuals to jointly make a decision without any centralized leadership, but only relying on local interactions (Judhi Prasetyo et al. 2019). They arise in the political arena (decisions by parliaments, governments, populations of voters), in the economic arena (decisions by management boards, boards of central banks), in the scientific arena (decision by ethical commissions, expert panels), in the legal arena (courts seeking a verdict). In the field of mechanics, a collective decision-making process can be influenced by two main driving forces: the 
agent's modulation as a response to different intrinsic qualities associated with the different options (Font Llenas et al. 2018), or a biasing component due to the environment in cases where options are not symmetrically accessible, meaning options have different costs associated with them (Montes de Oca et al. 2011; Scheidler et al. 2016)

In this paper, we study collective decision making by consensus in the political arena, in the issue of improving the electoral system of post-democratic societies (van Reybrouck 2016). We want to answer the theoretical (normative) question of how they could or should reach their decisions. A good collective decision should simultaneously meet two goals: it should suitably respect the group members views, and it should be internally coherent. Our theoretical analysis follows Arrow's theorem. This places us in the long tradition of social choice theory, going back at least to Arrow's $(1951 ; 1977)$ seminal contribution.

Arrow's theorem (Arrow, 1951) was a defining finding in the study mathematics of the mechanisms of aggregation of individual preferences into one collective preference. Recall that it shows that if these mechanisms satisfy certain conditions deemed a priori desirable, they can only be "dictatorial", that is to say conform to the preference of a single individual. By introducing in this area, on the one hand the formalism of relationship theory, on the other hand the axiomatic approach, and by showing the existence of impossible results in economics, Arrow was the initiator of a considerable body of research called the theory of social choice.

To choose the leaders on the basis of a consensus choice, every partner voices a position. All team members agree to support the ultimate decision, even when it's not everyone's favorite choice. Members strive to make the best decision for the group rather than competing for personal preferences. Then, all perspectives are taken into account, and the final decision is reached by group consensus.

More precisely, this study aims to model collective decision by concession, within the framework of the modernization of traditional Bantu governance practices. We start by explaining the concept of decision; we then analyze the mathematical model adapted to our research; we finally propose three indexes, namely the governing morality index (GMI), the index of national governance (ING), and the index of general governance (IGG).

\section{Material AND MeTHOD}

\subsection{The Science of Decision}

For most rationalist-analytical schools, decision is defined as a choice between several alternatives. Others say the decision also concerns the goal and alternative selection process. Cognitive approaches, finally, treat the decision as the result of an overall resolution process problems. The term decision has several definitions. It is assimilated to an act, an action or a problem solving process: a decision is an action that is taken to face a difficulty or respond to a modification of the environment, that is to say, to solve a problem that arise the individual or the organization (Levine 1990). Roy (1993) considers that the decision is often presented as the fact of an isolated individual (decision maker) who freely chooses between several possibilities of actions at some point in time.

A decision, whether individual or resulting from a group work, can be defined as commitment to an action, that is to say, a explicit intention to act (Mintzberg 1991).

According to Simon (1997), the examination of the nature of the decisions taken in the organization makes it possible to spread the decisions in the organization over the entire length of a ladder that goes at least normalized to most normalized.

The consensus decision modeling work that we are undertaking is an approach to decision support science. As a result, it incorporates a certain conception of the concepts of model, decision support, and actor.

\subsubsection{Model}

A model is a diagram which, for a field of questions, is taken as a representation of a class of phenomena, more or less skillfully removed from their context by an observer to serve as a support for investigation or communication. 


\subsubsection{Help with the Decision}

Decision support is the activity of someone who, using models clearly explained but not necessarily completely formalized, helps to obtain elements of answers to questions posed by a stakeholder in a decision process, elements contributing to favor, behavior likely to increase consistency between the evolution of the process on the one hand, the objectives and the value system at the service of which this stakeholder is placed on the other.

\subsubsection{Actors}

The actors, through their actions, directly condition the decision according to the value system they carry. An " $a$ " action is the representation of a possible contribution to the overall decision which, having regard to the state of the decision-making process, can be considered independently and serve as a point of application for the help with the decision.

Consequently, we can consider as scientific, any constructive step which operates in cooperation with actors. Under these conditions, validation can only take place with the actors concerned or with a group or community.

In fact, the science of decision support must develop a network of concepts, models, procedures and results capable of constituting a structured and coherent body of knowledge, playing the key role in guiding decision-making and communicate about it in accordance with goals and values. The model is not an objective reflection of reality but a rigorous construction which constitutes a vector of communication endowed with a certain number of properties, in a project of action and transformation which respects a certain number of values. It is not a question of discovering, or even approaching, an ideal decision, the optimality of which should be imposed on any actor who is sufficiently intelligent and in good faith. Correlatively, because it helps to build and not only to describe, decision support should favor a dynamic approach favoring a good integration in the decision process. In the case of the modernization of the practices of Bantu tradition governance, which concerns us here, decision support could thus contribute to the legitimization of the final decision.

In other words, in our philosophy, decision support is a general search for rigor, transparency and equal attention to the opinions of the different actors, which is also the concern of classic authors, notably Arrow, who are interested in the conditions of effectiveness and acceptability of democratic social choice procedures. This governance philosophy is structured around five points:

1. bringing out what is objective from what is less,

2. separating the robust conclusions from the fragile conclusions,

3. dissipating certain forms of misunderstanding in communication,

4. avoiding the trap of illusory reasoning,

5. highlighting non-controversial results when understood.

Action research engages the researcher in a program explicitly aimed at developing new solutions and thus testing the feasibility and properties of innovation. The intervening researcher must promote a better match between knowledge of the facts and the relationships they make possible between men.

\subsection{Rules for Choosing Leaders in Bantucracy}

Before being a body of systematized knowledge for the management of any field of human existence, governance is essentially the measured collection of elements which, each standing in its own place, allow the cohesion of together in a harmonious movement. It is the site of societal innovation and human development dynamism, because it is structured around interdependent practices and representations of the actors involved in the decision-making process, and the action of the various levels of power.

From the identity point of view, any society assumes a name and a history, occupies a defined territory, territory which it carries in the form of mental representation or awareness of belonging to a place. It is through this mental representation that the human group appropriates its place of existence and asserts its identity with regard to others.

From a material point of view, the governance of a society takes into account fulfillment in space and time, so that the measurement (in terms of quality and quantity) of governance is carried out with indices spatiotemporal. 
From an organizational point of view, governance includes traditions and institutions through which authority is exercised at political, economic, administrative, and regulatory levels, in the management of the affairs of a human group.

The general theory of governance to be exposed in this work has an encompassing objective, that of fundamental research. It is a question of analyzing and interpreting, in a scientific and normative way, the principles which allow human beings to conduct their individual, political, economic, social and cultural activities in the world in general, and in Africa in particular. If the world is understood as the whole constituted by human activities and consumable goods on the one hand, the mental representations (wish images) which condition and orient human groups on the other hand, inhabiting the world calls for its management and its transformation.

Then, the new electoral system in Bantucratie fundamentally corrects the structural weaknesses of the democratic system. Political parties become political associations which conceive, form and propagate ideas and new political values, the rights and freedoms of individuals and human groups in accordance with the Bantu ideal. In no case do they intervene either in the electoral system or in the system of citizen representation. In case of violation of this prohibition, the guilty association faces dissolution.

The electoral system, in this new context, establishes a real scale of representation, from the comtoise assembly to the federal parliament: one cannot become a federal deputy without having had a mandate as a comtoise deputy. The two principles of this elective system as well as of the decision-making system in the two assemblies, the comtoise assembly and the federal parliament, are consensus and the word given. Consensus can take the following two forms: either general consensus or weighted consensus in case it is not possible to obtain general consensus. Appeals fall within the competence of the judicial authority.

Then, no candidacy can be presented by any pretender under penalty of forfeiture. The final forfeiture will strike all those who try to corrupt the various institutions and resource people.

The very essence of Bantucracy is reconciliation, modernity and Bantu tradition. Also the traditional chiefs take part in the decisions of living together within the framework of the counties assemblies. They bring their sense of moderation and mediation, their traditional wisdom.

In order to avoid any individualism and above all to ensure equal representation of men and women in parliaments, any deputation is ensured by a couple (C). The choice of partners (C) takes place in two phases, namely the validation of applications and the election of applicants. In the territorial organization, the basic territorial entity is the basic community or the area of the city. The citizens' group is the assembly of residents of a grassroots community or the city district. The base community is a city or a grouping of villages which brings together at least 1,000 citizens. The same is true of the city district, which groups together several zones.

Only the group of citizens of a base community or a city district has the right to present the candidacy of a member of the comtoise assembly. No pretender can reveal himself of his own fact: such an attitude is worth the immediate rejection and the forfeiture of this pretender in the electoral system. In the citizens' group session, the citizens of the community or the neighborhood propose candidates. The whole freely examines the possibility and can only accept the candidacy of a couple by consensus, thus attesting to their unity before this decision.

There are 4 criteria required:

- the attachment of the partner with the base community and / or the district, the district and / or the district $(\alpha)$

- a rigorous and verified ethics of the two members of the coupled $(\beta)$

- $\quad$ knowledge of Bantu-Indigenous values $(\gamma)$

- the exercise of a continuous activity, a trade or a profession by each member of the pair $(\delta)$.

For our formalization, we will only use the ethical criterion.

In our modeling, the ethical criterion $\beta$ will be considered as the element around which the consensus should be achieved. The group of district or borough citizens must be convened in an extraordinary session in order to elect the paired deputy. During the meetings, it examines the candidacies submitted by the grassroots citizen groups. 
By consensus, the citizen group of the district or the borough chooses the coupled deputy who represents the district or the borough in the comtoise assembly. If general consensus is not obtained, the weighted consensus is implemented taking into account the majority obtained at the level of the grassroots citizen groups assembled.

The extraordinary session cannot end without having chosen the coupled deputy. In the event of incidents making choice impossible, the courts are seized on the spot and convictions are pronounced against the troublemakers for interference with living together. The consensus is then noted outside of the troublemakers.

Coupled deputies to the federal parliament are chosen by the comtoise assembly in extraordinary session. Coupled MPs subject to the federal election must already have a mandate in the comtoise assembly. Traditional leaders cannot be members of the federal parliament.

The candidacy of a paired deputy in the federal parliament is never presented by the paired concerned, but by a group of ten paired deputy. In plenary session, the collective must justify its choice.

After public examination, the comtoise assembly chooses the coupled deputy to sit in the federal parliament, either by general consensus or by weighted consensus.

The candidates validated for the post of prime minister of the federal government each present their program of action before the federal parliament, which is meeting in public session. At the hearing of the program, members of the federal parliament may ask questions to each candidate.

After hearing all the candidates, the consensual choice takes place. If no candidate obtains general consensus, a second round is organized, account is taken of the weighted consensus.

In conclusion, the decision-making process by consensus for the choice of leaders takes place in 4 stages:

1. proposal from the list of candidates and discussion on the admissibility of applications

2. voters fill in the ethics sheet

3. calculation of the moral index of each candidate

4. discussions on the results and choice of the elected representative by consensus

\section{RESULTS AND DISCUSSION}

\subsection{The Mathematical Model}

In his book Social choice and individual values, Kenneth Arrow tried to propose a method of aggregation $f$ of the preferences of the voters democratically acceptable, to finally lead to his theorem of impossibility. We present a proof of this theorem using the notion of decisive group. Within the issue of our modeling, the decisive group corresponds to the 5 moral values retained $(\beta)$, in the context of traditional Bantu governance.

Our goal is therefore to formulate an aggregation function $f$, acceptable by consensus, which verifies, at a minimum, the 4 principles of rationality proposed by Arrow. Let us clarify these principles.

\section{The principle of consensus or the sovereignty of opinion}

Let $\Psi$ be the set of 3 criteria which make up the 5 criteria of the morality of rulers, other than the $\beta$ criterion of ethics. We denote $\Psi=(\alpha, \delta, \gamma)$.

Let us admit that the ethical criterion $\beta$ is composed of 5 essential elements of ethics in Bantu traditions, namely:

$\beta_{1}=$ respect for God and the ancestors;

$\beta_{2}=$ respect and protection of life;

$\beta_{3}=$ respect for the property of others and public property;

$\beta_{4}=$ respect for the family and sexual morality;

$\beta_{5}=$ respect for the word given .

Then, the principle of consensus establishes two rules: 
First of all, the 4 criteria are in no way restricted in the classification of alternatives, which means that all the $S_{i}$ criteria are authorized.

Second, in the classification of the 4 criteria of the morality of rulers, it is accepted to classify alternative $\beta$ (of the five moral values retained) before alternative $\Psi$ (of other values). Then $\beta$ will be ranked in front of $\Psi$, after aggregation. In other words, if for any moral criterion $m_{i}$, we have $\beta S_{i} \Psi$, then $S=f(P)$ must necessarily rank $\beta$ before $\Psi\left(\beta S_{i} \Psi\right)$. Note that, since all the criteria are authorized, the domain of definition of the aggregation function $f$ is $\vartheta^{n}$ whole, and not a restriction. In addition, the principle of consensus ensures the subjectivity of the function $f$. Indeed, let $S \in \theta$, consider the profile $P=(S, \ldots, S)$, then:

$f(P)=S$.

\section{2 indifference to irrelevant alternatives}

This principle makes it possible not to worry about the forgotten alternatives (because a priori not relevant): the addition of an alternative must not change the order of the other alternatives. In other words, if we consider a subset of alternatives, the function $f$ must not lead to another classification on this subset.

That is, for any part $Z$ of $A, f(P(Z))=f(P(A))$ restrictaZ.

\section{Monotonous binary independence}

This principle reflects the fact that the more voters agree to prefer $x$ to $y$, the more there $x$ is likely to be effectively preferred over $y$ after aggregation. If this principle was not respected, a candidate could lose elections because too many voters would have wanted him to win.

More precisely, let be two profiles $P$ and $P^{\prime}$, let $S=f(P)$ and $S^{\prime}=f\left(P^{\prime}\right)$.

Let there be two alternatives $x$ and $y$ such as $x S y$.

Note to the set of all voters preferring $x$ to $y$ in $P$, if in $P^{\prime}$ the voters of $A$ also rank $x$ before $y$ then $x S^{\prime} y$.

\section{The dictatorship of ethical criteria}

How to create a choice of leaders by consensus without forbidding dictatorship of ethical criteria? More specifically, there must be a moral criterion $m_{i}$ for whom his preference over a any couple of alternatives implies that the aggregate preference for that couple is the same. In other words:

$$
\exists i \in \llbracket 1, n \rrbracket, \forall(\beta, \psi) \in A^{2}, \beta S_{i} \Psi \rightarrow \beta S \psi .
$$

\section{Concept of decisive group}

If by applying the 4 principles of rationality on particular profiles, we can identify properties on $f$. This would limit the possibilities for aggregation.

Now consider $\beta$ and $\psi$ two alternatives. In an attempt to construct the function $f$ and taking into account the third principle of rationality (binary monotonous independence), a crucial question arises fairly quickly: How many voters must agree to classify $\beta$ before $\psi$ so that in the end, after aggregation, we have $\beta S \psi$ ? This question leads us logically to pose the following definition of decisive group:

Consider $\beta$ and $\psi$ two alternatives, $K \subset V$ is a decisive group $K_{f}^{\beta \psi}$

if $\quad\left(\forall_{m_{i}} \in K, \beta S_{i} \psi\right) \rightarrow \beta S \psi$

In other words, a group is said to be decisive on these two alternatives if its unanimous or consensual ranking corresponds to the aggregated ranking.

Note 1: The decisive groups obviously depend on alternatives $\beta$ and $\psi$ but also on the aggregation method $f$.

Note 2: From the second principle, the decisive groups do not depend on the other alternatives.

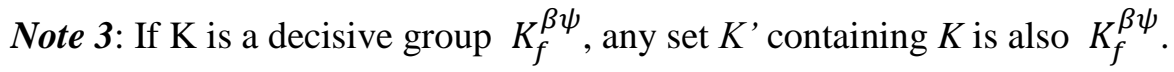


Note 4: From the third principle, so that $K$ is a $K_{f}^{\beta \psi}$, it suffices that there exists a profile $P$ for which: -each voter of $K$ places $\beta$ before $\psi$

-each voter outside $K$ place $\psi$ before $\beta$

-in the end $\beta S \psi$.

Note 5: According to the principle of unanimity or consensus, for any couple $(\beta ; \psi)$ of alternatives, $V$ is a $K_{f}^{\beta \psi}$

\section{Lemma 1}

We will now demonstrate a first lemma of which here is to state it:

Any $K_{f}^{\beta \psi}$ decisive set of cardinal greater than or equal to 2 contains a strictly smaller decisive set.

\section{Lemma 2}

As we noticed a little earlier, the principle of unanimity or consensus assures us that the set $V$ of all voters is a decisive group. By applying Lemma 1 to maximum $n-1$ time we obtain a decisive group having only one character; and this allows us to state Lemma 2:

There is at least one decisive group with only one voter.

\section{Arrow's theorem of impossibility}

We now have all the tools to demonstrate the Arrow impossibility theorem:

There is no democratically acceptable method of aggregation. In other words, dictatorship is the one and only aggregation method verifying at the same time "the principle of unanimity", "the principle of indifference to irrelevant alternatives" and "the principle of binary monotonous independence"!

\section{Evidence :}

We will show that if $f$ satisfies principles 1,2 and 3 , then $f$ satisfies the fourth principle, that is to say there is a dictator.

By applying lemmas 1 and 2, we already know that there is a voter $\varepsilon$ which is a decisive group. Let's say that $\varepsilon$ is a $K_{f}^{\beta \psi}$.

To show that $\varepsilon$ is a dictator, just see that $\varepsilon$ is a $K_{f}^{x y}$ for any couple of alternatives $(x ; y)$.

Consider the following $P_{1}$ profile:

The voter $\varepsilon$ ranks $x$ before $\beta$ before $\psi: x S_{\varepsilon \beta} S_{\varepsilon \psi}$

The other voters rank $\psi$ before $x$ before $\beta: \psi S_{i x} S_{i \beta}$

The order $S=f\left(P_{1}\right)$ check $\beta S \psi$ since $\varepsilon$ is a $K_{f}^{\beta \psi}$. But also $x S \beta$ unanimously (principle 1 )

By transitivity of $S$ we thus have $x S \beta S \psi$. But since $\varepsilon$ is the only voter to put $x$ before $\psi, \varepsilon$ is a $K_{f}^{x \psi}$.

Now consider the following $P_{2}$ profile:

The voter $\varepsilon$ ranks $x$ before $\psi$ before $y: x S_{\varepsilon \psi} S_{\varepsilon y}$

The other voters rank $\psi$ before $y$ before $x: \psi S_{i y} S_{i x}$

The order $S=f\left(P_{2}\right)$ check $x S \psi$ since $\varepsilon$ is a $K_{f}^{x \psi}$ but also $\psi S y$ by unanimity.

By transitivity of $S$ we thus have $x S \psi S y$. But since $\varepsilon$ is the only voter to put $x$ before $y, \varepsilon$ is a $K_{f}^{x y}$. We have just demonstrated that there is necessarily a voter $\varepsilon$ who is a $K_{f}^{x y}$ for any couple $(x ; y)$ alternatives; $\varepsilon$ is therefore a dictator, which ends the demonstration.

\subsection{Indexes Modeling}

\subsubsection{Governing Morality Index (GMI)}

We assign numerical values to the four criteria retained for the GMI:

- attachment of the partner with the base community and / or the district, the district and / or the district $(\alpha)=10$ 
- a rigorous and verified ethics of the two members of the coupled $(\beta)=70$

- $\quad$ knowledge of Bantu-Indigenous values $(\gamma)=10$

- the exercise of a continuous activity, a trade or a profession by each member of the pair $(\delta)=10$.

So the total is 100 .

We distribute the numerical value 70 of the dictating criterion $\beta$ of morality according to the elements that compose it:

$\beta_{1}=$ respect for God and the ancestors $=20$

$\beta_{2}=$ respect and protection of life $=20$

$\beta_{3}=$ respect for the property of others and public property $=10$

$\beta_{4}=$ respect for the family and sexual morality $=10$

$\beta_{5}=$ respect for the word given $=10$

Then $\beta=\beta_{1}+\beta_{2}+\beta_{3}+\beta_{4}+\beta_{5}$;

$\beta=20+20+10+10+10$;

$\beta=70$

Let's remember that $\psi=\alpha+\gamma+\delta$;

$\psi=10+10+10$;

$\psi=30$

From the above, we therefore retain that 10 is the minimum numerical value and 70 is the maximum numerical value. Then:

$\mathrm{GMI}=\frac{\text { Dictator criteria-the other criteria }}{\text { maximum numerical value-minimum numerical value }}$

In our case:

$$
\mathrm{GMI}=\frac{\beta-\psi}{70-10}
$$

If $\beta=70$ and $\psi=30$;

$\mathrm{GMI}=\frac{70-30}{70-10}=\frac{40}{60}=0,6666666667 \simeq 0,67$

We can conclude that the highest GMI of a candidate by consensus, in the context of Bantucracy, is:

$$
\text { GMI }=67 \%
$$

\subsubsection{National Governance Index (NGI)}

We propose to calculate the national governance index from the arithmetic mean of two indexes, namely Gross Domestic Product (GDP) and Human Development Index (HDI).

Gross Domestic Product (GDP) is the monetary value, in local currency, of all final economic goods and services produced in a country during a specific period of time. It is the broadest financial measurement of a nation's total economic activity. The total goods and services bought by consumers encompass all private expenditures, government spending, investments, and net exports. Below are three different approaches to the GDP formula.

\section{The GDP formula}

There are two primary methods or formulas by which GDP can be determined:

\section{Expenditure Approach}

The most commonly used GDP formula, which is based on the money spent by various groups that participate in the economy. 
$\mathrm{GDP}=\mathrm{C}+\mathrm{G}+\mathrm{I}+\mathrm{NX}$

$\mathrm{C}=$ consumption or all private consumer spending within a country's economy, including, durable goods (items with a lifespan greater than three years), non-durable goods (food \& clothing), and services.

$\mathrm{G}=$ total government expenditures, including salaries of government employees, road construction/repair, public schools, and military expenditure.

$\mathrm{I}=$ sum of a country's investments spent on capital equipment, inventories, and housing.

$\mathrm{NX}=$ net exports or a country's total exports less total imports.

\section{Income Approach}

This GDP formula takes the total income generated by the goods and services produced.

GDP $=$ Total National Income + Sales Taxes + Depreciation + Net Foreign Factor Income

Total National Income - the sum of all wages, rent, interest, and profits.

Sales Taxes : consumer taxes imposed by the government on the sales of goods and services.

Depreciation : cost allocated to a tangible asset over its useful life.

Net Foreign Factor Income :the difference between the total income that a country's citizens and companies generate in foreign countries, versus the total income foreign citizens and companies generate in that country.

\section{Human Development Index (HDI)}

The Human Development Index (HDI) provides a single index measure to capture three key dimensions of human development: a long and healthy life, access to knowledge and a decent standard of living.

The HDI utilizes four key metrics:

life expectancy at birth : to assess a long and healthy life

expected years of schooling : to assess access to knowledge of the young generation

average years of schooling : to assess access to knowledge of the older generation

gross national income (GNI) per capita : to assess the standard of living

HDI $=\left(I_{\text {Helth }} * I_{\text {Education }} * I_{\text {Income }}\right)^{1 / 3}$

Then:

$$
\mathrm{NGI}=(G D P+H D I)^{1 / 2}
$$

\subsubsection{General Governance Index (GGI)}

We propose to calculate the national governance index from the arithmetic mean of two indexes, namely Governing Morality Index (GMI) and the National Governance Index (IGN).

$$
\text { GGI }=(G M I+I G N)^{1 / 2}
$$

\section{CONCLUSION}

The modeling of collective decision-making by consensus that we have just examined can only be applied in the context of an acceptance of the moral values of traditional Bantu governance. Bantucracy is a solution to replace the fall of modern democracy.

Indeed, Bantucracy theory examines, in a fair way, the distribution of rights, obligations and powers that support human organizations. Bantucracy theory studies modes of coordination which underlie the various activities of an organization and which ensure their coherence; explores sources of organizational dysfunction or maladjustment to the environment that lead to limited performance; 
establishing benchmarks, creating tools and sharing knowledge. Ultimately, Bantucracy theory helps organizations to renew themselves when their governance system is weak, by proposing the calculation of the general governance index (IGG) based on the governing morality index (IMG) and the national governance index (IGN).

\section{REFERENCES}

[1] Achen, C. H., \& Bartels, L. M. 2016. Democracy for Realists: Why Elections Do Not Produce Responsive Government. Princeton, NJ: Princeton University Press.

[2] Arrow, K.J. 1951. Social choice and individual values, New York, Wiley.

[3] Arrow, K.J. 1977. Currents developments in the theory of social choice, Social Research 44: 607-622.

[4] Boundja, C. 2019. Modern Democracy and Traditional Bantu Governance: Towards an Alternative Policy. Advances in Politics and Economic, 2 (2): 166-180.

[5] Foa, R. S., \& Mounk, Y. 2016. The danger of deconsolidation. The democratic disconnect. Journal of Democracy, 27(3): 5-18.

[6] Font L., A., Talamali, M. S., Xu, X., Marshall, J. A. R., \& Reina, A. 2018. Quality sensitive foraging by a robot swarm through virtual pheromone trails. In M. Dorigo, M. Birattari, C. Blum, A. L. Christensen, A. Reina, \& V. Trianni (Eds.), Swarm intelligence, LNCS 11172: 135-149. Berlin: Springer.

[7] Lévine P., \& J. Pomerol 1990. Systèmes interactifs d'aide à la décision et systèmes experts. Paris, Editions Hermès.

[8] Mintzberg, H. 1991. The effective organization: forces and forms. Sloan Management Review, Winter: 54-67.

[9] Montes de Oca, M. A., Ferrante, E., Scheidler, A., Pinciroli, C., Birattari, M., \& Dorigo, M. 2011. Majorityrule opinion dynamics with differential latency: A mechanism for self- organized collective decisionmaking. Swarm Intelligence, 5: 305-327.

[10] Peter, F. 2011. Democratic legitimacy. New York: Routledge.

[11] Prasetyo, J., De Masi, G. \& Ferrante, E. 2019, Collective decision making in dynamic environments. Swarm Intelligence 13:217-243

[12] Roy, B. 1993. Decision science or decision-aid science?, European Journal of Operational Research, (66) 2:184-203.

[13] Scheidler, A., Brutschy, A., Ferrante, E., \& Dorigo, M. 2016. The k-unanimity rule for self-organized decision-making in swarms of robots. IEEE Transactions on Cybernetics, 46(5):1175-1188.

[14] Simon, H.A. 1997. Administrative behaviour: a study of Decision-Making process in Administrative Organizations. Free Press: New York.

[15] Széll, G. 2018. Democracy and participation in the twenty-first century. International Review of Sociology, 28(2) : 209-215.

[16] Van Reybrouck, D. 2016. Against elections: The case for democracy. London: Bodley Head.

[17] Warren, M. E. 2017. A Problem-Based Approach to Democratic Theory. American political Review 111(1) : 39-53.

\section{AUTHOR'S BIOGRAPHY}

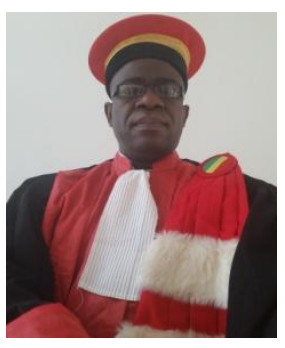

Claver BOUNJA, Professor of Philosophy and Development Sciences. Coordinator of the Laboratory for Multidisciplinary Studies and Research in Human Sciences and Environment (LERPSHE), Marien Ngouabi University, Congo. Political Governance Manager of the Thematic Research and Governance Program of the African and Malagasy Council for Higher Education (PTRGD/CAMES)

Citation: Prof. Claver Boundja. "Modeling of Political Governance Indexes in the Issue of Collective Decision-Making by Consensus" International Journal of Humanities Social Sciences and Education (IJHSSE), vol 7, no. 6, 2020, pp. 15-25. doi: http://dx.doi.org/10.20431/2349-0381.0706003.

Copyright: () 2020 Authors. This is an open-access article distributed under the terms of the Creative Commons Attribution License, which permits unrestricted use, distribution, and reproduction in any medium, provided the original author and source are credited. 